\title{
Klebsiella pneumoniae pneumonia in patients with rheumatic autoimmune diseases: clinical characteristics, antimicrobial resistance and factors associated with extended-spectrum $\beta$ - lactamase production
}

Yang Liu, Yecheng Liu, Jiayuan Dai, Anlei Liu, Yi Li, Jun Xu, Xuezhong Yu, Jihai Liu* and Huadong Zhu*†

\begin{abstract}
Background: Over the past decades, Klebsiella pneumoniae (K. pneumoniae) infections have been increasing and affected immunocompromised patients nosocomially and communally, with extended-spectrum $\beta$-lactamase (ESBL) production becoming a major concern. Patients with rheumatic autoimmune diseases, mostly receiving immunosuppressive therapy, are vulnerable to various infections, including K. pneumoniae. However, few have investigated $K$. pneumoniae infections in this specific population. This study aimed to identify factors associated with ESBL production and mortality of $K$. pneumoniae pneumonia among patients with rheumatic autoimmune diseases in the Emergency Department.

Methods: We retrospectively investigated patients with rheumatic diseases who were diagnosed with $K$. pneumoniae pneumonia. The diagnosis of K. pneumoniae pneumonia was based on clinical manifestations, radiological findings and microbiological testing results. Prognostic factors and risk factors for ESBL production were determined with univariate and multivariate logistic regression analysis. Empirical therapy and antimicrobial susceptibility data were also collected.

(Continued on next page)
\end{abstract}

\footnotetext{
* Correspondence: liujihai1977@aliyun.com; zhdpumch@outlook.com

${ }^{\dagger}$ Jihai Liu and Huadong Zhu contributed equally to this work.

Department of Emergency Medicine, Peking Union Medical College Hospital,

Peking Union Medical College, Chinese Academy of Medical Sciences, 1

Shuaifuyuan, Dongcheng District, Beijing, China
}

C C The Author(s). 2021 Open Access This article is licensed under a Creative Commons Attribution 4.0 International License, which permits use, sharing, adaptation, distribution and reproduction in any medium or format, as long as you give appropriate credit to the original author(s) and the source, provide a link to the Creative Commons licence, and indicate if changes were made. The images or other third party material in this article are included in the article's Creative Commons licence, unless indicated otherwise in a credit line to the material. If material is not included in the article's Creative Commons licence and your intended use is not permitted by statutory regulation or exceeds the permitted use, you will need to obtain permission directly from the copyright holder. To view a copy of this licence, visit http://creativecommons.org/licenses/by/4.0/ The Creative Commons Public Domain Dedication waiver (http://creativecommons.org/publicdomain/zero/1.0/) applies to the data made available in this article, unless otherwise stated in a credit line to the data. 
(Continued from previous page)

Results: Of 477 K. pneumoniae pneumonia patients, 60 were enrolled into this study. The in-hospital mortality was 28.3\%. Septic shock, ICU admission, the need for mechanical ventilation and change of antibiotics due to clinical deterioration, all related to mortality, were included as unfavorable clinical outcomes. Multivariate analysis suggested that ESBL production (OR, 6.793; $p=0.012)$, initial $P C T \geq 0.5 \mathrm{ng} / \mathrm{ml}(\mathrm{OR}, 5.024 ; p=0.033)$ and respiratory failure at admission $(\mathrm{OR}, 4.401 ; p=0.046)$ predicted increased mortality. ESBL production was significantly associated with dose of corticosteroids (OR, 1.033; $p=0.008)$ and CMV viremia $(O R, 4.836 ; p=0.032)$ in patients with rheumatic autoimmune diseases. Abnormal leukocyte count $(\mathrm{OR}, 0.192 ; p=0.036)$ was identified as a protective factor of ESBLproducing K. pneumoniae pneumonia. The most commonly used empirical antibiotic was ceftazidime, while most isolates showed less resistance to carbapenems and amikacin in susceptibility testing.

Conclusions: K. pneumoniae pneumonia could be life-threatening in patients with rheumatic autoimmune diseases. Our findings suggested that ESBL production, initial PCT $\geq 0.5 \mathrm{ng} / \mathrm{ml}$ and respiratory failure at admission were independent factors associated with poor prognosis. Dose of corticosteroids and CMV viremia, predicting ESBL production in K. pneumoniae pneumonia, may help make individualized antibiotic decisions in clinical practice.

Keywords: Klebsiella pneumoniae pneumonia, Rheumatic autoimmune diseases, ESBL, Mortality, Corticosteroids, Antimicrobial resistance

\section{Introduction}

Klebsiella pneumoniae (K. pneumoniae) is classically an opportunistic bacterial pathogen. When first recognized, it was usually encountered in hospital-acquired infections, and has been extensively studied in hospitalized individuals [1-3]. In the past decades, community-associated infections with $K$. pneumoniae have been increasing, and pose a threat especially to immunocompromised patients. Individuals with rheumatic autoimmune diseases, mostly receiving immunosuppressive therapy, are vulnerable to this opportunistic infection. K. pneumoniae causes various infections including pneumonia. Mortality in K. pneumoniae pneumonia ( $K p$ pneumonia) has been reported as high as $50 \%[4,5]$. It is suggested that outcomes in patients with Gram-negative bacterial (GNB) infections can be significantly improved if timely appropriate antibiotic therapy is provided [6]. While $\beta$-lactam antibiotics, especially third-generation cephalosporins, are frequently used to treat GNB infections including $K p$ pneumonia, a dramatic increase in antibiotic resistance has happened over the past decades, with resistance to $\beta$-lactams having the greatest impact on therapeutic effectiveness [4]. Thus, extended-spectrum $\beta$-lactamases (ESBL) producing $K$. pneumoniae, able to hydrolyze the antibiotic $\beta$-lactam ring, has become a major concern in clinical practice.

ESBL production in $K$. pneumoniae is generally believed to be associated with unfavorable outcomes, including extended length of hospital stay, increased mortality and in-hospital expenses, which has been investigated in $K$. pneumoniae bacteremia and healthcareassociated pneumonia [7-10]. However, some other studies did not demonstrate the correlation between ESBL production and mortality $[11,12]$. With regard to
ESBL acquisition, risk factors include previous use of antibiotics, prolonged hospitalization, ICU stay and mechanical ventilation, as has been reported previously [4, 13]. Nevertheless, limited data are available about antimicrobial resistance and clinical outcomes of $K p$ pneumonia among patients with rheumatic diseases.

In the present study, we retrospectively investigated clinical characteristics and outcomes of $K p$ pneumonia, as well as risk factors for ESBL-producing K. pneumoniae, among patients with rheumatic autoimmune diseases.

\section{Methods \\ Study population}

This study investigated patients with rheumatic autoimmune diseases who were admitted from Emergency Department and diagnosed with pneumonia caused by K. pneumoniae between January 2013 and December 2019 at Peking Union Medical College Hospital, a tertiary care hospital in Beijing, China.

\section{Microbiology}

Microbiology testing was carried out in the Department of Laboratory Medicine at Peking Union Medical College Hospital. Antimicrobial susceptibility testing was carried out by broth microdilution methods per Clinical and Laboratory Standards Institution (CLSI) guidelines [14], and the antimicrobial agents tested included amoxicillin-clavulanic acid, amikacin, aztreonam, cefepime, cefperazone-sulbactam, ceftazidime, ceftriaxone, cefuroxime, ciprofloxacin, ertapenem, gentamicin, imipenem, levofloxacin, meropenem, minocycline, piperacillin-tazobactam, sulfamethoxazole trimethoprim and tigecycline. Susceptibility testing results were interpreted using latest CLSI clinical breakpoints [15]. 
Production of ESBLs was screened using the disk diffusion method as per CLSI document M100-S29 [15].

"Intermediate" and "resistant" strains in antimicrobial susceptibility testing were defined as "non-susceptible" isolates. Patients with more than one culture of respiratory tract specimens, at least one strain showing ESBL production, were included in the ESBL-positive group. Carbapenem-resistant $K$. pneumoniae isolates were defined as those resistant to any of the following carbapenems: ertapenem, meropenem or imipenem (MIC $\geq 4 \mu \mathrm{g}$ / $\mathrm{mL})$.

\section{Data collection and definitions}

Medical records were retrospectively reviewed and the following data were extracted from the hospital's electronic database: (1) clinical characteristics, including age, sex, underlying disease, immunosuppressive medication, comorbidity, clinical manifestation and disease course; (2) laboratory findings, including blood leukocyte count, urea, C-reactive protein, lactate dehydrogenase, procalcitonin (PCT) and virus PCR assay; (3) microbiological results, including smear and culture of respiratory tract specimen, ESBL production and antimicrobial susceptibility pattern.

Since isolation of $K$. pneumoniae from sputum may not be indicative of pneumonia, the diagnosis of $K p$ pneumonia was based on clinical manifestations (such as fever, "currant jelly" sputum or pleuritic chest pain), radiological findings (such as typical alveolar consolidation on chest computed tomography), and microbiological test results.

The daily dosage of corticosteroids was expressed as the prednisone equivalent $(1 \mathrm{mg}$ of prednisone equals $0.8 \mathrm{mg}$ of methylprednisolone which equals $1 \mathrm{mg}$ of prednisolone). Corticosteroid pulse therapy referred to intravenous methylprednisolone at dosages of 500-1000 $\mathrm{mg}$ for 3-5 consecutive days. Cytomegalovirus (CMV) viremia was defined as plasma CMV-DNA > 500 copies/ $\mathrm{ml}$ by quantitative PCR. Respiratory failure at admission was defined as admission $\mathrm{PaO}_{2}$ lower than $60 \mathrm{mmHg}$ with or without $\mathrm{PaCO}_{2}$ higher than $50 \mathrm{mmHg}$ while breathing room air [16].

\section{Statistical analysis}

Statistical analyses were performed using Stata 14.0 SE or GraphPad Prism 6.0. The variables in the datasets were presented as mean \pm SD or number and proportion of the total (\%). Continuous variables were analyzed by Mann-Whitney U test. Categorical variables were analyzed with Chi-square test or Fisher's exact test, as appropriate. Given the number of cases available, variables were carefully chosen for multivariate analysis. With clinical relevance taken into account, variables found significant $(p<0.05)$ in univariate analysis were selected by the least absolute shrinkage and selection operator (LASSO) and were further examined in the multivariate logistic regression model.

\section{Ethical approval}

This study conformed to the Declaration of Helsinki and was approved by the Medical Ethics Committee of Peking Union Medical College Hospital. Written informed consent for inclusion from each patient was waived by the Medical Ethics Committee of Peking Union Medical College Hospital because this was a retrospective study, and no study-related interventions were included.

\section{Results}

\section{Patient characteristics}

During the study period, 477 patients present to the Emergency Department were diagnosed with $K p$ pneumonia. Among these patients, 63 were identified as suffering from rheumatic autoimmune diseases. Three of them, treated as out-patients, were excluded from our analysis due to incomplete medical records. Within the included cohort (60 patients), 20 (33.3\%) had systemic lupus erythematosus (SLE), 9 (15\%) had polymyositis or dermatomyositis (PM/DM), and 8 (13.3\%) had vasculitis. Other underlying autoimmune disorders are listed in Table 1. Females accounted for $60 \%$ of all the cases, and $80 \%$ of patients had a history of hospitalization within the previous 90 days. Fifty-eight patients (96.7\%) were receiving corticosteroids, among which $8(13.3 \%)$ had been given pulse therapy within 1 month before $K p$ pneumonia. The mean duration of corticosteroid administration was $22.9 \pm 46.2$ months, and an average dose of $52.2 \pm 42.6 \mathrm{mg} / \mathrm{d}$ equivalent prednisone was administered

Table 1 Underlying rheumatic autoimmune diseases in patients with Kp pneumonia

\begin{tabular}{ll}
\hline Rheumatic autoimmune diseases & $\mathbf{N = 6 0}$ \\
\hline SLE & $20(33 \%)$ \\
PM/DM & $9(15 \%)$ \\
Vasculitis & $8(13 \%)$ \\
Undifferentiated CTD & $6(10 \%)$ \\
pSS & $5(8 \%)$ \\
RA & $4(7 \%)$ \\
ASD & $3(5 \%)$ \\
SSC & $2(3 \%)$ \\
Primary APS & $1(2 \%)$ \\
Overlap syndrome & $1(2 \%)$ \\
PMR & $1(2 \%)$
\end{tabular}

The case of overlap syndrome included features of SLE and PM

Data were presented as numbers (\%)

SLE systemic lupus erythematosus, PM/DM polymyositis/dermatomyositis, CTD connective tissue disease, $p S S$ primary Sjögren syndrome, $R A$ rheumatoid arthritis, ASD adult Still's disease, SSC systemic sclerosis, APS antiphospholipid syndrome, $P M R$ polymyalgia rheumatica 
at the time of diagnosis. In combination with corticosteroids, immunosuppressants was used in 25 patients (41.7\%). The ICU admission rate was $63.3 \%$, and the inhospital mortality rate was $28.3 \%$ in the study cohort (Table 2).

\section{Prognostic factors}

Unfavorable clinical outcomes included in-hospital death, as well as septic shock, ICU admission, the need for mechanical ventilation and change of antibiotics due to clinical deterioration, which were strongly related to mortality. Thus, in order to identify prognostic factors for $K p$ pneumonia among patients with rheumatic autoimmune diseases, 43 survivors were compared with 17 non-survivors. As is shown in Table 2, respiratory failure at admission was significantly more prevalent in nonsurvivors $(p=0.036)$. The level of blood urea $(p=0.011)$ and PCT $(p=0.012)$ were also associated with prognosis. ESBL production $(p=0.012)$ was related to increased mortality. Multivariate logistic regression suggested ESBL production (OR, 6.793; 95\% CI, 1.533-30.102), initial $\mathrm{PCT} \geq 0.5 \mathrm{ng} / \mathrm{ml}$ (OR, 5.024; 95\% CI, 1.138-22.189) and respiratory failure at admission (OR, 4.401; 95\% CI, 1.030-18.808) were independent predictors of unfavorable outcomes (Table 3).

\section{Empirical therapy and antimicrobial susceptibility pattern of $K$. pneumoniae isolates}

The most common empirical antibiotic was ceftazidime ( $n=18,30 \%)$. Thirteen patients were administered with ceftazidime alone $(21.7 \%)$ and 5 were treated in combination with amikacin or moxifloxacin (8.3\%). Imipenem $(n=9,15 \%)$ and cefperazone-sulbactam $(n=8,13.3 \%)$, following ceftazidime, were also frequently used as empirical therapy. Figure 1 demonstrated antimicrobial treatments that were administered empirically.

According to antimicrobial susceptibility testing, most isolates were less resistant to carbapenems (6.7-8.3\%) and amikacin $(10.0 \%)$, while highly resistant to ciprofloxacin $(56.7 \%)$. Ceftazidime resistance was observed in $36.7 \%$ isolates of K. pneumoniae (Table 4, Fig. 2).

\section{Factors associated with ESBL-positive $K p$ pneumonia}

As ESBL production was associated with mortality, we further investigated risk factors for ESBL-producing $K p$ pneumonia. In this study, 23 patients had ESBL-positive $K p$ pneumonia, while 32 had ESBL-negative $K p$ pneumonia (Table 5). Cases with $K$. pneumoniae strains resistant to carbapenems $(n=5)$ were excluded from the analysis. At the time of diagnosis, patients in ESBL-positive group were receiving higher doses of corticosteroids, as compared to those in ESBL-negative group $(p=0.015)$. Blood leukocyte count was also related to ESBL production $(p=0.035)$. The number of lymphocytes were significantly lower in patients with ESBL-producing $K p$ pneumonia $(p=0.015)$. However, no significant difference was observed in the number of neutrophils between the two groups. Patients with CMV viremia $(p=0.009)$ were more likely to be infected with ESBL-producing $K$. pneumoniae. Whether antibiotics were received within previous 30 days did not show a significant difference in ESBL production in this cohort. By multivariate analysis, dose of corticosteroids (OR, 1.033; 95\% CI, 1.008-1.059) and CMV viremia (OR, 4.836; 95\% CI, 1.142-20.480) were identified as independent variables associated with ESBL production, while abnormal leukocyte count (OR, 0.192; 95\% CI, 0.041-0.901) was an independent protective factor of ESBL-positive $K p$ pneumonia (Table 6).

\section{Discussion}

K. pneumoniae, as a clinically relevant pathogen, has been well studied in hospitalized patients [4]. Individuals with rheumatic autoimmune diseases, mostly receiving corticosteroids, are rendered immunocompromised and may also be susceptible to K. pneumoniae. However, few have investigated $K p$ pneumonia in this specific population. In this study, we comprehensively reviewed the clinical and laboratory findings of $K p$ pneumonia in patients with rheumatic autoimmune diseases.

Corticosteroid use comes with a number of wellestablished risks including infections. It has been reported a daily dose of $5 \mathrm{mg}$ equivalent prednisone increases the risk for hospitalized pneumonia, with a higher risk at doses greater than $10 \mathrm{mg}$ daily [17]. A meta-analysis of 42 observational studies in patients with rheumatoid arthritis (RA) or inflammatory polyarthritis found that the use of systemic corticosteroid therapy was associated with an increased risk of infection in a dose-dependent manner [18]. The duration of corticosteroid therapy is also important, but less well-defined [19]. In our cohort, a daily dose of $52.2 \pm 42.6 \mathrm{mg}$ equivalent prednisone, which was a relatively high dose, was administered prior to the diagnosis of $K p$ pneumonia. The duration of corticosteroid administration was $22.9 \pm 46.2$ months. Nevertheless, neither the dose nor the duration of corticosteroid therapy was associated with prognosis of $K p$ pneumonia in patients with rheumatic autoimmune diseases.

In the attempt to identify prognostic factors, our data showed that initial $\mathrm{PCT} \geq 0.5 \mathrm{ng} / \mathrm{ml}$ significantly predicted in-hospital death. PCT is a useful biomarker to distinguish bacterial infection from other causes of infection. In a meta-analysis of 14 trials and 4211 patients with respiratory tract infection, initial PCT levels were associated with an increased risk of treatment failure and mortality, especially in the emergency department setting [20]. An 
Table 2 Clinical characteristics and comparisons between survivors and non-survivors

\begin{tabular}{|c|c|c|c|c|}
\hline Variables & $\begin{array}{l}\text { Total } \\
(N=60)\end{array}$ & $\begin{array}{l}\text { Non-survivors } \\
(N=17)\end{array}$ & $\begin{array}{l}\text { Survivors } \\
(N=43)\end{array}$ & $p$ value \\
\hline Age (years) & $51.2 \pm 17.9$ & $47.2 \pm 21.2$ & $52.8 \pm 16.4$ & 0.465 \\
\hline Sex (female) & $36(60.0 \%)$ & $11(64.7 \%)$ & $25(58.1 \%)$ & 0.640 \\
\hline Corticosteroid use & $58(96.7 \%)$ & $16(94.1 \%)$ & $42(97.7 \%)$ & 0.490 \\
\hline Pulse therapy & $8(13.3 \%)$ & $3(17.6 \%)$ & $5(11.6 \%)$ & 0.676 \\
\hline Duration of corticotherapy (months) & $22.9 \pm 46.2$ & $36.8 \pm 70.6$ & $17.4 \pm 31.5$ & 0.913 \\
\hline Dose of corticosteroids (mg) & $52.2 \pm 42.6$ & $51.2 \pm 36.4$ & $52.5 \pm 45.2$ & 0.944 \\
\hline Immunosuppressants & $25(41.7 \%)$ & $9(52.9 \%)$ & $16(37.2 \%)$ & 0.265 \\
\hline Hospitalization within last 90 days & $48(80.0 \%)$ & $13(76.5 \%)$ & $35(81.4 \%)$ & 0.726 \\
\hline Previous antimicrobial therapy within 30 days & $52(86.7 \%)$ & $16(94.1 \%)$ & $36(83.7 \%)$ & 0.420 \\
\hline Ever-smokers & $15(25.0 \%)$ & $2(11.8 \%)$ & $13(30.2 \%)$ & 0.192 \\
\hline Pulmonary diseases ${ }^{\mathrm{a}}$ & $29(48.3 \%)$ & $8(47.1 \%)$ & $21(48.8 \%)$ & 1.000 \\
\hline Hypertension & $22(36.7 \%)$ & $8(47.1 \%)$ & $14(32.6 \%)$ & 0.376 \\
\hline Diabetes mellitus & $14(23.3 \%)$ & $4(23.5 \%)$ & $10(23.3 \%)$ & 1.000 \\
\hline Fever & $45(75.0 \%)$ & $14(82.4 \%)$ & $31(72.1 \%)$ & 0.520 \\
\hline Cough/expectoration & $49(81.7 \%)$ & $11(64.7 \%)$ & $38(88.4 \%)$ & 0.059 \\
\hline Initial body temperature $\left({ }^{\circ} \mathrm{C}\right)$ & $37.40 \pm 0.99$ & $37.44 \pm 1.15$ & $37.38 \pm 0.94$ & 0.722 \\
\hline Mean arterial pressure $(\mathrm{mmHg})$ & $90.9 \pm 17.3$ & $89.3 \pm 18.1$ & $91.6 \pm 17.2$ & 0.785 \\
\hline Respiratory failure at admission & $26(43.3 \%)$ & $11(64.7 \%)$ & $15(34.9 \%)$ & 0.036 \\
\hline Blood leukocyte count $\left(10^{9} / \mathrm{L}\right)$ & $10.01 \pm 5.60$ & $9.89 \pm 5.74$ & $10.06 \pm 5.61$ & 0.994 \\
\hline Blood neutrophil count $\left(10^{9} / \mathrm{L}\right)$ & $8.69 \pm 5.29$ & $8.61 \pm 5.35$ & $8.72 \pm 5.34$ & 0.993 \\
\hline Blood lymphocyte count $(/ \mu \mathrm{L})$ & $867 \pm 978$ & $877 \pm 1300$ & $863 \pm 836$ & 0.450 \\
\hline Albumin $(\mathrm{g} / \mathrm{L})$ & $29.8 \pm 4.8$ & $28.7 \pm 5.1$ & $30.2 \pm 4.6$ & 0.352 \\
\hline Alanine aminotransferase $(\mathrm{U} / \mathrm{L})$ & $82.3 \pm 282.8$ & $48.8 \pm 53.0$ & $95.8 \pm 333.8$ & 0.847 \\
\hline Creatinine $(\mu \mathrm{mol} / \mathrm{L})$ & $83.8 \pm 81.3$ & $81.9 \pm 59.3$ & $84.5 \pm 89.3$ & 0.854 \\
\hline Urea $(\mathrm{mmol} / \mathrm{L})$ & $9.41 \pm 6.65$ & $12.33 \pm 7.72$ & $8.22 \pm 5.86$ & 0.011 \\
\hline C-reactive protein (mg/L) & $71.2 \pm 63.6$ & $78.3 \pm 67.8$ & $67.1 \pm 62.0$ & 0.407 \\
\hline Lactate dehydrogenase $(\mathrm{U} / \mathrm{L})$ & $537.6 \pm 424.8$ & $710.0 \pm 588.5$ & $425.5 \pm 227.2$ & 0.146 \\
\hline PCT (ng/ml) & & & & 0.012 \\
\hline$<0.5$ & $39(65.0 \%)$ & $7(41.2 \%)$ & $32(74.4 \%)$ & \\
\hline $0.5-2$ & $9(15.0 \%)$ & $2(11.8 \%)$ & $7(16.3 \%)$ & \\
\hline $2-10$ & $9(15.0 \%)$ & $6(35.3 \%)$ & $3(7.0 \%)$ & \\
\hline$>10$ & $3(5.0 \%)$ & $2(11.8 \%)$ & $1(2.3 \%)$ & \\
\hline CMV viremia & $19(31.7 \%)$ & $8(47.1 \%)$ & $11(25.6 \%)$ & 0.107 \\
\hline ESBL production & $22 / 51(43.1 \%)$ & 10/14 (71.4\%) & 12/37 (32.4\%) & 0.012 \\
\hline Carbapenem resistance & $5(8.3 \%)$ & $2(11.8 \%)$ & $3(7.0 \%)$ & 0.616 \\
\hline Bacteremia & $11(18.3 \%)$ & $5(29.4 \%)$ & $6(14.0 \%)$ & 0.265 \\
\hline \multicolumn{5}{|l|}{ Outcomes } \\
\hline Change of antibiotics due to clinical deterioration & $22(36.7 \%)$ & $12(70.6 \%)$ & $10(23.3 \%)$ & 0.001 \\
\hline Septic shock & $14(23.3 \%)$ & $10(58.8 \%)$ & $4(9.3 \%)$ & $<0.001$ \\
\hline ICU admission & $38(63.3 \%)$ & $16(94.1 \%)$ & $22(51.2 \%)$ & 0.002 \\
\hline Mechanical ventilation & $26(43.3 \%)$ & $15(88.2 \%)$ & $11(25.6 \%)$ & $<0.001$ \\
\hline Length of ICU stay (days) & $17.6 \pm 19.5$ & $16.2 \pm 14.8$ & $18.6 \pm 22.7$ & 0.939 \\
\hline Length of hospital stay (days) & $27.5 \pm 20.9$ & $20.5 \pm 17.5$ & $30.4 \pm 21.7$ & 0.103 \\
\hline
\end{tabular}


Table 2 Clinical characteristics and comparisons between survivors and non-survivors (Continued)

\begin{tabular}{|c|c|c|c|c|}
\hline Variables & $\begin{array}{l}\text { Total } \\
(N=60)\end{array}$ & $\begin{array}{l}\text { Non-survivors } \\
(N=17)\end{array}$ & $\begin{array}{l}\text { Survivors } \\
(N=43)\end{array}$ & $p$ value \\
\hline In-hospital mortality & $17(28.3 \%)$ & & & \\
\hline
\end{tabular}

observational study also found that PCT was related to illness severity in patients with severe pneumonia, including community-acquired pneumonia (CAP), ventilator-associated pneumonia (VAP) and hospitalacquired pneumonia (HAP) [21]. Therefore, our findings among patients with rheumatic autoimmune diseases are consistent with previous studies in general population. In the present study, respiratory failure at admission $\left(\mathrm{PaO}_{2}<60 \mathrm{mmHg}\right)$ was developed in $43.3 \%$ of the patients and was found to be an independent prognostic factor of $K p$ pneumonia in patients with rheumatic autoimmune diseases. Pneumonia Severity Index (PSI), which includes $\mathrm{PaO}_{2}<60 \mathrm{mmHg}$ as a parameter, is an effective tool in assessing severity of illness in patients with CAP [22]. Another observational study showed that low $\mathrm{PaO}_{2}$ in the first $24 \mathrm{~h}$ after admission was associated with in-hospital mortality in ICU patients [23]. The rationale could be that an abnormally low level of oxygen in blood (hypoxemia) may fail to meet the metabolic demands of certain tissues, which would adversely affect multiple organs and eventually lead to poor prognosis. ESBL production in K. pneumoniae is one of the important mechanisms for its antibiotic resistance. Infections caused by ESBLproducing $K$. pneumoniae are associated with higher rates of treatment failure and increased mortality [7, $8,10]$, which presents a threat especially to immunocompromised patients. In contrast, a recent study in neutropenic patients with bloodstream infection failed to show the contribution of ESBL production to mortality risk [12]. In our cohort with pulmonary infection, patients infected with ESBL-producing $K$. pneumoniae had a higher mortality rate compared to those with non-ESBL-producing $K$. pneumoniae infection. It is possible that ESBL production may potentially lead to delayed appropriate therapy or even treatment failure, which has a negative impact on patient clinical outcomes [6].

Factors associated with ESBL production were assessed among patients with rheumatic autoimmune diseases. Hospitalization and previous use of antibiotics are considered to be risk factors for drugresistant infection mediated by ESBLs [12, 24]. However, in this study, with regard to hospitalization (within previous 90 days) and receipt of antibiotics (within previous 30 days), we have not found statistically significant differences in ESBL production. Instead, dose of corticosteroid therapy was an independent risk factor for ESBL-positive $K p$ pneumonia. It has been reported that corticosteroid use is correlated with ESBL production in nosocomial infections and bloodstream infections by several studies [25-27]. In this pneumonia cohort, the majority of the patients were receiving corticosteroids, and those administered with higher doses were more likely to be infected with ESBL-positive $K$. pneumoniae, which may be explained by hyperglycemia and impaired cellular immunity associated with corticosteroid use [28, 29]. High concentrations of corticosteroids can suppress signals mediated by pattern recognition receptors and cytokine receptors, and inhibit the production of $\mathrm{B}$ cells and $\mathrm{T}$ cells. In addition, interestingly, CMV viremia was also identified as a significant predictor of ESBL-positive $K p$ pneumonia. CMV infection and reactivation occurs frequently in immunocompromised patients and critically ill immunocompetent patients and has been reportedly associated with adverse clinical outcomes $[30,31]$. The possible explanation for our findings may be that CMV viremia reflects more severe immunosuppression and critically ill condition, under

Table 3 Factors associated with in-hospital mortality from Kp pneumonia

\begin{tabular}{|c|c|c|c|c|c|c|}
\hline \multirow[t]{2}{*}{ Variables } & \multicolumn{3}{|l|}{ Univariate } & \multicolumn{3}{|l|}{ Multivariate } \\
\hline & Odds ratio & $95 \% \mathrm{Cl}$ & $p$ value & Odds ratio & $95 \% \mathrm{Cl}$ & $p$ value \\
\hline ESBL production & 4.800 & $1.341-17.186$ & 0.016 & 6.793 & $1.533-30.102$ & 0.012 \\
\hline Initial PCT $\geq 0.5$ (ng/ml) & 4.156 & $1.272-13.581$ & 0.018 & 5.024 & $1.138-22.189$ & 0.033 \\
\hline Respiratory failure at admission & 3.422 & $1.056-11.092$ & 0.040 & 4.401 & $1.030-18.808$ & 0.046 \\
\hline
\end{tabular}

Cl confidence interval 


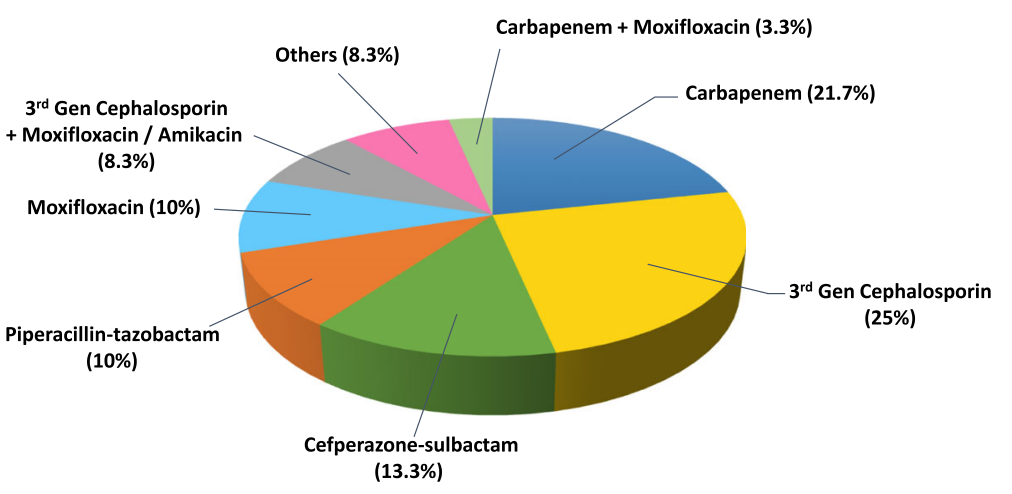

Fig. 1 Empirical antimicrobial therapy administered to patients with Kp pneumonia

which patients are more vulnerable to drug-resistant infections.

Empirical antimicrobial therapy included thirdgeneration cephalosporins (primarily ceftazidime), carbapenems, followed by cefperazone-sulbactam and piperacillin-tazobactam. Ceftazidime is frequently used to treat $K p$ pneumonia in general population and is mostly effective in ESBL-negative infections. However, in patients with underlying autoimmune disorder, ESBLpositive infections could be prevalent, and empirical therapy with ceftazidime could result in treatment

Table 4 Antimicrobial susceptibility pattern of $K$. pneumoniae isolates

\begin{tabular}{lll}
\hline Antibiotics & Susceptibility $(\boldsymbol{N}=\mathbf{6 0})$ & Resistance \\
\cline { 2 - 3 } Imipenem & $56(93.3 \%)$ & $6.7 \%$ \\
Meropenem & $55(91.7 \%)$ & $8.3 \%$ \\
Ertapenem & $55(91.7 \%)$ & $8.3 \%$ \\
Amikacin & $54(90.0 \%)$ & $10.0 \%$ \\
Tigecycline & $48(80.0 \%)$ & $20.0 \%$ \\
Cefperazone-sulbactam & $44(73.3 \%)$ & $26.7 \%$ \\
Piperacillin-tazobactam & $40(66.7 \%)$ & $33.3 \%$ \\
Gentamicin & $39(65.0 \%)$ & $35.0 \%$ \\
Ceftazidime & $38(63.3 \%)$ & $36.7 \%$ \\
Cefepime & $37(61.7 \%)$ & $38.3 \%$ \\
Aztreonam & $34(56.7 \%)$ & $43.3 \%$ \\
Amoxicillin-clavulanic acid & $33(55.0 \%)$ & $45.0 \%$ \\
Ceftriaxone & $31(51.7 \%)$ & $48.3 \%$ \\
Levofloxacin & $30(50.0 \%)$ & $50.0 \%$ \\
Minocycline & $30(50.0 \%)$ & $50.0 \%$ \\
Sulfamethoxazole trimethoprim & $29(48.3 \%)$ & $51.7 \%$ \\
Cefuroxime & $27(45.0 \%)$ & $55.0 \%$ \\
Ciprofloxacin & $26(43.3 \%)$ & $56.7 \%$ \\
\hline
\end{tabular}

Strains showing "intermediate" in antimicrobial susceptibility testing were included as "non-susceptible" isolates

Resistance (\%) = 1- susceptibility (\%) failure. According to susceptibility testing, most isolates were less resistant to carbapenems, which could make them the preferred options for $K p$ pneumonia. In clinical practice, carbapenems are frequently used in treating ESBL-associated infections and are recommended to be administered to immunocompromised patients (corticosteroid use $>15 \mathrm{mg}$ of prednisone daily for $>2$ weeks) [32]. However, overuse of carbapenems and subsequent selective pressure can contribute to the spread of carbapenem-resistant $K$. pneumoniae. Therefore, empirical antibiotics should be selected cautiously. In patients with rheumatic autoimmune diseases, our findings suggested dose of corticosteroids and CMV viremia, predicting ESBL production in $K p$ pneumonia, may help make individualized antibiotic decisions.

There are some potential limitations of this study. First, the sample size was relatively small. We included pneumonia patients with rheumatic autoimmune diseases who were admitted from Emergency Department. Since a few patients were transferred from other hospitals, they may

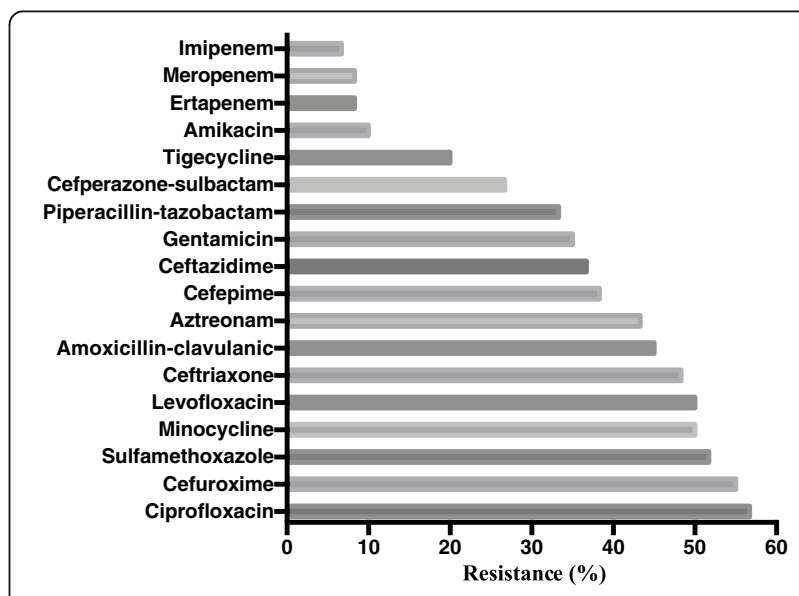

Fig. 2 Antimicrobial resistance pattern of K. pneumoniae isolates 
Table 5 Characteristics of patients with rheumatic diseases and pneumonia caused by K. pneumoniae with or without ESBL production

\begin{tabular}{|c|c|c|c|}
\hline Variables & $\begin{array}{l}\text { ESBL-positive } \\
(N=23)\end{array}$ & $\begin{array}{l}\text { ESBL-negative } \\
(N=32)\end{array}$ & $p$ value \\
\hline Age (years) & $48.0 \pm 14.6$ & $54.2 \pm 18.0$ & 0.096 \\
\hline Sex (female) & $14(60.9 \%)$ & $17(53.1 \%)$ & 0.568 \\
\hline $\begin{array}{l}\text { Duration of corticotherapy } \\
\text { (months) }\end{array}$ & $17.5 \pm 37.0$ & $29.3 \pm 54.2$ & 0.444 \\
\hline Dose of corticosteroids (mg) & $72.3 \pm 53.3$ & $37.6 \pm 28.4$ & 0.015 \\
\hline $\begin{array}{l}\text { Hospitalization within last } 90 \\
\text { days }\end{array}$ & $20(87.0 \%)$ & $23(71.9 \%)$ & 0.182 \\
\hline $\begin{array}{l}\text { Previous antimicrobial } \\
\text { therapy within } 30 \text { days }\end{array}$ & $22(95.7 \%)$ & $25(78.1 \%)$ & 0.120 \\
\hline Diabetes mellitus & $5(21.7 \%)$ & $9(28.1 \%)$ & 0.592 \\
\hline Fever & $19(82.6 \%)$ & $23(71.9 \%)$ & 0.355 \\
\hline Cough/expectoration & $18(78.3 \%)$ & $27(84.4 \%)$ & 0.726 \\
\hline $\begin{array}{l}\text { Respiratory failure at } \\
\text { admission }\end{array}$ & $10(43.5 \%)$ & $14(43.8 \%)$ & 0.984 \\
\hline $\begin{array}{l}\text { Blood leukocyte count }\left(10^{9} \text { / }\right. \\
\text { L) }\end{array}$ & & & 0.035 \\
\hline$<4$ & $3(13.0 \%)$ & $4(12.5 \%)$ & \\
\hline $4-10$ & $14(60.9 \%)$ & $9(28.1 \%)$ & \\
\hline$>10$ & $6(26.1 \%)$ & $19(59.4 \%)$ & \\
\hline $\begin{array}{l}\text { Blood neutrophil count }\left(10^{9} \text { / }\right. \\
\text { L) }\end{array}$ & $8.17 \pm 5.99$ & $9.13 \pm 5.03$ & 0.246 \\
\hline $\begin{array}{l}\text { Blood lymphocyte count } \\
(/ \mu \mathrm{L})\end{array}$ & $516 \pm 291$ & $1143 \pm 1255$ & 0.015 \\
\hline Albumin (g/L) & $28.9 \pm 4.8$ & $30.2 \pm 4.9$ & 0.259 \\
\hline Urea (mmol/L) & $9.71 \pm 5.61$ & $8.99 \pm 7.37$ & 0.187 \\
\hline C-reactive protein (mg/L) & $66.0 \pm 59.8$ & $79.0 \pm 69.7$ & 0.703 \\
\hline $\mathrm{PCT}(\mathrm{ng} / \mathrm{ml})$ & & & 0.899 \\
\hline$<0.5$ & $15(65.2 \%)$ & 20 (62.5\%) & \\
\hline $0.5-2$ & $3(13.0 \%)$ & $6(18.8 \%)$ & \\
\hline $2-10$ & 4 (17.4\%) & $4(12.5 \%)$ & \\
\hline$>10$ & 1 (4.4\%) & $2(6.2 \%)$ & \\
\hline CMV viremia & 12 (52.2\%) & $6(18.8 \%)$ & 0.009 \\
\hline
\end{tabular}

Data were presented as mean \pm SD or numbers (\%)

have hospital-acquired pneumonia. Due to limited cases, we did not perform subgroup analysis based on where the pneumonia was acquired. Nevertheless, the data did provide a general picture in the Emergency setting. Second, it was a retrospective study performed in a single institution. Some medical records had missing data, which may affect the results. The susceptibility pattern of $K$. pneumoniae isolates may vary in other centers and regions. However, as the data were collected from one center, the testing method for susceptibility and ESBL detection was consistent. Third, when evaluating clinical outcomes, we mainly assessed in-hospital mortality but not long-term survival
Table 6 Risk factors associated with ESBL-positive Kp pneumonia in patients with rheumatic autoimmune diseases

\begin{tabular}{|c|c|c|c|c|c|c|}
\hline \multirow[t]{2}{*}{ Variables } & \multicolumn{3}{|c|}{ Univariate } & \multicolumn{3}{|c|}{ Multivariate } \\
\hline & $\begin{array}{l}\text { Odds } \\
\text { ratio }\end{array}$ & $95 \% \mathrm{Cl}$ & $p$ value & $\begin{array}{l}\text { Odds } \\
\text { ratio }\end{array}$ & $95 \% \mathrm{Cl}$ & $p$ value \\
\hline $\begin{array}{l}\text { Dose of } \\
\text { corticosteroids } \\
(\mathrm{mg})\end{array}$ & 1.024 & $\begin{array}{l}1.005- \\
1.042\end{array}$ & 0.011 & 1.033 & $\begin{array}{l}1.008- \\
1.059\end{array}$ & 0.008 \\
\hline $\begin{array}{l}\text { Abnormal } \\
\text { leukocyte count }\end{array}$ & 0.252 & $\begin{array}{l}0.081- \\
0.785\end{array}$ & 0.017 & 0.192 & $\begin{array}{l}0.041- \\
0.901\end{array}$ & 0.036 \\
\hline $\begin{array}{l}\text { Blood lymphocyte } \\
\text { count }(/ \mu \mathrm{L})\end{array}$ & 0.198 & $\begin{array}{l}0.038- \\
1.036\end{array}$ & 0.055 & & & \\
\hline CMV viremia & 4.727 & $\begin{array}{l}1.414- \\
15.809\end{array}$ & 0.012 & 4.836 & $\begin{array}{l}1.142- \\
20.480\end{array}$ & 0.032 \\
\hline
\end{tabular}

Cl confidence interval

${ }^{a}$ Abnormal leukocyte count was defined as leukocyte count $<4 \times 10^{9} / \mathrm{L}$ or leukocyte count $>10 \times 10^{9} / \mathrm{L}$.

of $K p$ pneumonia patients with rheumatic autoimmune diseases.

\section{Conclusions}

In summary, $K p$ pneumonia could affect immunocompromised individuals and is potentially fatal. In patients with rheumatic autoimmune diseases, initial $\mathrm{PCT} \geq 0.5$ $\mathrm{ng} / \mathrm{ml}$, respiratory failure at admission and ESBL production predicted increased mortality. The most important factors found to be associated with ESBL-producing $\mathrm{Kp}$ pneumonia were dose of corticosteroids and CMV viremia, while abnormal leukocyte count was identified as a protective factor of ESBL-positive $K p$ pneumonia in this specific population. Well-designed prospective studies are required to validate the current findings.

\section{Abbreviations \\ Kp: Klebsiella pneumoniae; ESBL: Extended-spectrum B-lactamase; GNB: Gram- negative bacteria; CLSI: Clinical and Laboratory Standards Institution; PCT: Procalcitonin; CMV: Cytomegalovirus; LASSO: Least absolute shrinkage and selection operator; SLE: Systemic lupus erythematosus; PM: Polymyositis; DM: Dermatomyositis; CTD: Connective tissue disease; pSS: Primary Sjögren syndrome; RA: Rheumatoid arthritis; ASD: Adult Still's disease; SSc: Systemic sclerosis; APS: Antiphospholipid syndrome; PMR: Polymyalgia rheumatica; OR: Odds ratio; Cl: Confidence interval; CAP: Community-acquired pneumonia; VAP: Ventilator-associated pneumonia; HAP: Hospital-acquired pneumonia; PSI: Pneumonia Severity Index}

\section{Acknowledgments}

Thanks to members of Clinical Laboratory for technical help, especially to Meng Xiao for helping us go through the original data and explaining the methodology in detail.

\section{Authors' contributions}

H. Zhu and Y. Liu conceived the idea. Y. Liu and J. Dai collected the data. Y. Liu, A. Liu, J. Xu and X. Yu performed the analysis and interpreted the results. Y. Liu and YC. Liu drafted the manuscript. J. Liu and Y. Li made the revision. J. Liu and H. Zhu supervised the study and made the decision for submission. All the authors reviewed and approved the final manuscript.

\section{Funding}

This study was supported by Science Foundation of Peking Union Medical College Hospital for young scholars (Grant number: pumch201911884). 


\section{Availability of data and materials}

The datasets analyzed during the current study are available from the corresponding author H.Z. or J.L. on reasonable request.

\section{Declarations}

\section{Ethics approval and consent to participate}

The study was approved by the Medical Ethics Committee of Peking Union Medical College Hospital. Written informed consent was waived by the Medical Ethics Committee of Peking Union Medical College Hospital due to the anonymized retrospective nature of the analysis.

\section{Consent for publication}

Not applicable.

\section{Competing interests}

The authors declare that they have no conflicts of interest.

\section{Received: 14 November 2020 Accepted: 6 April 2021}

\section{Published online: 17 April 2021}

\section{References}

1. Magill SS, Edwards JR, Bamberg W, Beldavs ZG, Dumyati G, Kainer MA, et al. Multistate point-prevalence survey of health care-associated infections. N Engl J Med. 2014;370(13):1198-208. https://doi.org/10.1056/NEJMoa1306801.

2. Pena C, Pujol M, Ardanuy C, Ricart A, Pallares R, Linares J, et al. An outbreak of hospital-acquired Klebsiella pneumoniae bacteraemia, including strains producing extended-spectrum beta-lactamase. J Hosp Infect. 2001;47(1):539. https://doi.org/10.1053/jhin.2000.0862.

3. Ranjbar R, Fatahian Kelishadrokhi A, Chehelgerdi M. Molecular characterization, serotypes and phenotypic and genotypic evaluation of antibiotic resistance of the Klebsiella pneumoniae strains isolated from different types of hospital-acquired infections. Infect Drug Resist. 2019;12: 603-11. https://doi.org/10.2147//DR.S199639.

4. Martin RM, Bachman MA. Colonization, infection, and the accessory genome of Klebsiella pneumoniae. Front Cell Infect Microbiol. 2018;8:4. https://doi.org/10.3389/fcimb.2018.00004.

5. Podschun R, Ullmann U. Klebsiella spp. as nosocomial pathogens: epidemiology, taxonomy, typing methods, and pathogenicity factors. Clin Microbiol Rev. 1998;11(4):589-603. https://doi.org/10.1128/CMR.11.4.589.

6. Bonine NG, Berger A, Altincatal A, Wang R, Bhagnani T, Gillard P, et al. Impact of delayed appropriate antibiotic therapy on patient outcomes by antibiotic resistance status from serious gram-negative bacterial infections. Am J Med Sci. 2019;357(2):103-10. https://doi.org/10.1016/j.amjms.2018.11. 009.

7. Friedman ND, Temkin E, Carmeli Y. The negative impact of antibiotic resistance. Clin Microbiol Infect. 2016;22(5):416-22. https://doi.org/10.1016/j. cmi.2015.12.002.

8. Lautenbach E, Patel JB, Bilker WB, Edelstein PH, Fishman NO. Extendedspectrum beta-lactamase-producing Escherichia coli and Klebsiella pneumoniae: risk factors for infection and impact of resistance on outcomes. Clin Infect Dis. 2001;32(8):1162-71. https://doi.org/10.1086/31 9757.

9. Kang Cl, Chung DR, Ko KS, Peck KR, Song JH, Korean Network for Study of Infectious D. Risk factors for infection and treatment outcome of extendedspectrum beta-lactamase-producing Escherichia coli and Klebsiella pneumoniae bacteremia in patients with hematologic malignancy. Ann Hematol. 2012;91(1):115-21. https://doi.org/10.1007/s00277-011-1247-7.

10. Lee MK, Kim SH, Yong SJ, Shin KC, Park HC, Choi J, et al. Clinical and microbiological features of patients admitted to the intensive care unit with nursing and healthcare-associated pneumonia. J Int Med Res. 2015;43(2): 236-49. https://doi.org/10.1177/0300060514551188.

11. Marra AR, Wey SB, Castelo A, Gales AC, Cal RG, Filho JR, et al. Nosocomial bloodstream infections caused by Klebsiella pneumoniae: impact of extended-spectrum beta-lactamase (ESBL) production on clinical outcome in a hospital with high ESBL prevalence. BMC Infect Dis. 2006;6(1):24. https://doi.org/10.1186/1471-2334-6-24.

12. Ben-Chetrit E, Eldaim MA, Bar-Meir M, Dodin M, Katz DE. Associated factors and clinical outcomes of bloodstream infection due to extended-spectrum beta-lactamase-producing Escherichia coli and Klebsiella pneumoniae during febrile neutropenia. Int J Antimicrob Agents. 2019;53(4):423-8. https://doi.org/10.1016/.ijantimicag.2018.12.003.

13. Kim SH, Kwon JC, Choi SM, Lee DG, Park SH, Choi JH, et al. Escherichia coli and Klebsiella pneumoniae bacteremia in patients with neutropenic fever: factors associated with extended-spectrum beta-lactamase production and its impact on outcome. Ann Hematol. 2013;92(4):533-41. https://doi.org/10.1 007/s00277-012-1631-y.

14. M07ED11E CaLSI. Methods for dilution antimicrobial susceptibility tests for bacteria that grow aerobically; approved standard. 11th ed. Wayne: Clinical and Laboratory Standards Institute; 2018.

15. M100ED29E CaLSI. Performance standards for antimicrobial susceptibility testing: 29th informational supplement. Wayne: Clinical and Laboratory Standards Institute; 2019.

16. Shebl E, Burns B. Respiratory failure. In: StatPearls. edn. Treasure Island; 2020.

17. Wolfe F, Caplan L, Michaud K. Treatment for rheumatoid arthritis and the risk of hospitalization for pneumonia: associations with prednisone, diseasemodifying antirheumatic drugs, and anti-tumor necrosis factor therapy. Arthritis Rheum. 2006;54(2):628-34. https://doi.org/10.1002/art.21568.

18. Dixon WG, Suissa S, Hudson M. The association between systemic glucocorticoid therapy and the risk of infection in patients with rheumatoid arthritis: systematic review and meta-analyses. Arthritis Res Ther. 2011;13(4): R139. https://doi.org/10.1186/ar3453.

19. Youssef J, Novosad SA, Winthrop KL. Infection risk and safety of corticosteroid use. Rheum Dis Clin N Am. 2016;42(1):157-176, ix-x. https:// doi.org/10.1016/j.rdc.2015.08.004

20. Kutz A, Briel M, Christ-Crain M, Stolz D, Bouadma L, Wolff M, et al. Prognostic value of procalcitonin in respiratory tract infections across clinical settings. Crit Care. 2015;19(1):74. https://doi.org/10.1186/s13054-0150792-1.

21. Bloos F, Marshall JC, Dellinger RP, Vincent JL, Gutierrez G, Rivers E, et al. Multinational, observational study of procalcitonin in ICU patients with pneumonia requiring mechanical ventilation: a multicenter observational study. Crit Care. 2011;15(2):R88. https://doi.org/10.1186/cc10087.

22. Fine MJ, Auble TE, Yealy DM, Hanusa BH, Weissfeld LA, Singer DE, et al. A prediction rule to identify low-risk patients with community-acquired pneumonia. N Engl J Med. 1997;336(4):243-50. https://doi.org/10.1056/ NEJM199701233360402.

23. de Jonge E, Peelen L, Keijzers PJ, Joore H, de Lange D, van der Voort PH, et al. Association between administered oxygen, arterial partial oxygen pressure and mortality in mechanically ventilated intensive care unit patients. Crit Care. 2008;12(6):R156. https://doi.org/10.1186/cc7150.

24. Nepal K, Pant ND, Neupane B, Belbase A, Baidhya R, Shrestha RK, et al. Extended spectrum beta-lactamase and metallo beta-lactamase production among Escherichia coli and Klebsiella pneumoniae isolated from different clinical samples in a tertiary care hospital in Kathmandu, Nepal. Ann Clin Microbiol Antimicrob. 2017;16(1):62. https://doi.org/10.1186/s12941-017-023 6-7.

25. Silva N, Oliveira M, Bandeira AC, Brites C. Risk factors for infection by extended-spectrum beta-lactamase producing Klebsiella pneumoniae in a tertiary hospital in Salvador, Brazil. Braz J Infect Dis. 2006;10(3):191-3. https:// doi.org/10.1590/s1413-86702006000300007.

26. Lee JA, Kang Cl, Joo EJ, Ha YE, Kang SJ, Park SY, et al. Epidemiology and clinical features of community-onset bacteremia caused by extended-spectrum beta-lactamase-producing Klebsiella pneumoniae. Microb Drug Resist. 2011;17(2):267-73. https://doi.org/10.1089/mdr.2010. 0134

27. Anesi JA, Lautenbach E, Tamma PD, Thom KA, Blumberg EA, Alby K, et al. Risk factors for extended-spectrum beta-lactamase-producing Enterobacterales bloodstream infection among solid organ transplant recipients. Clin Infect Dis. 2020;72(6):953-60. https://doi.org/10.1093/cid/ ciaa190.

28. Tamez-Perez HE, Quintanilla-Flores DL, Rodriguez-Gutierrez R, GonzalezGonzalez JG, Tamez-Pena AL. Steroid hyperglycemia: prevalence, early detection and therapeutic recommendations: a narrative review. World J Diabetes. 2015;6(8):1073-81. https://doi.org/10.4239/wjd.v6.i8.1073.

29. Cain DW, Cidlowski JA. Immune regulation by glucocorticoids. Nat Rev Immunol. 2017;17(4):233-47. https://doi.org/10.1038/nri.2017.1.

30. Jaber S, Chanques G, Borry J, Souche B, Verdier R, Perrigault PF, et al. Cytomegalovirus infection in critically ill patients: associated factors and consequences. Chest. 2005;127(1):233-41. https://doi.org/10.1378/chest.12 7.1.233. 
31. Limaye AP, Kirby KA, Rubenfeld GD, Leisenring WM, Bulger EM, Neff MJ, et al. Cytomegalovirus reactivation in critically ill immunocompetent patients. Jama. 2008;300(4):413-22. https://doi.org/10.1001/jama.3 00.4.413.

32. Gutierrez-Gutierrez B, Rodriguez-Bano J. Current options for the treatment of infections due to extended-spectrum beta-lactamaseproducing Enterobacteriaceae in different groups of patients. Clin Microbiol Infect. 2019;25(8):932-42. https://doi.org/10.1016/j.cmi.2019. 03.030 .

\section{Publisher's Note}

Springer Nature remains neutral with regard to jurisdictional claims in published maps and institutional affiliations.

Ready to submit your research? Choose BMC and benefit from:

- fast, convenient online submission

- thorough peer review by experienced researchers in your field

- rapid publication on acceptance

- support for research data, including large and complex data types

- gold Open Access which fosters wider collaboration and increased citations

- maximum visibility for your research: over $100 \mathrm{M}$ website views per year

At $\mathrm{BMC}$, research is always in progress.

Learn more biomedcentral.com/submissions 